J. Clin. Chem. Clin. Biochem.

Vol. 20, 1982, pp. 893-898

\title{
Accurate Quantification of Nonesterified and Total Cholesterol in Plasma and Urine from Crude Lipid Extracts by Stable Isotope Dilution and Field Desorption Mass Spectrometry
}

\author{
By W. D. Lehmann and M. Kessler \\ Abteilung Medizinische Biochemie, Institut für Physiologische Chemie, Universitäts-Krankenhaus-Eppendorf, \\ Hamburg
}

(Received March 11/July 1, 1982)

Summary: Levels of free and total cholesterol were quantified in control sera and human urine using $\left[{ }^{2} \mathrm{H}_{7}\right]$ cholesterol or $\left[{ }^{13} \mathrm{C}_{2}\right]$ cholesterol as internal standard and field desorption mass spectrometry for the quantification. These analyses are performed using a crude chloroform extract without chromatographic separation of the constituents. Due to the extremely soft ionization conditions in field desorption, the constituents of the crude lipid extract predominantly form molecular ion species and only a very low amount of fragment ions of low relative abundance thus minimizing the possibility of ion overlap in the mass spectrum. Mass spectrometric quantification of cholesterol in two control sera resulted in data within the range of assigned concentrations. The standard deviations of the mass spectrometric data were around $\pm 2 \%$. Generally, $50 \mu \mathrm{l}$ of serum or plasma or $500 \mu \mathrm{l}$ of urine are extracted and the mass spectrometric quantification performed using an aliquot of 2-10\%. A characteristic pattern of intact cholesteryl esters is also obtained.

\section{Quantifizierung von freiem und Gesamt-Cholesterin in Plasma und Urin aus rohen Lipid-Extrakten mit Stabil-Isotopenverdünnung und Felddesorptions-Massenspektrometrie}

Zusammenfassuing: Freies Cholesterin und Gesamtcholesterin wurden in Kontrollseren und in Urin mit Felddesorptions-Massenspektrometrie und $\left[{ }^{2} \mathrm{H}_{7}\right]$ Cholesterin oder $\left[{ }^{13} \mathrm{C}_{2}\right]$ Cholesterin als internem Standard quantifiziert. Diese Bestimmungen werden mit einem rohen Chloroform-Extrakt ohne chromatographische Auftrennung der Bestandteile durchgeführt. Aufgrund der extrem schonenden Ionisierungsbedingungen bei der Felddesorption bilden die Komponēnten des Lipidextraktes überwiegend Molekülionen und nur wenige Fragmentionen von geringer relativer Häufigkeit, so daß die Wahrscheinlichkeit des Überlagems von Ionensignalen minimiert ist. Die massenspektrometrische Quantifizierung von Cholesterin in zwei Kontrollseren ergab Werte innerhalb des Vertrauensbereiches der Sollwerte. Die Standardabweichung der massenspektrometrischen Daten ist etwa $\pm 2 \%$. Typischerweise werden $50 \mu l$ Serum oder Plasma oder $500 \mu l$ Urin extrahiert und die massenspektrometrische Bestimmung wird mit einem 2-10\% Aliquot des Gesamtextraktes durchgeführt. Ein charakteriștisches Muster der intakten Cholesterinester wird ebenfalls erhalten.

\section{Introduction}

Assays based on isotope dilution and mass spectrometry play an important role among recommended and candidate reference methods in clinical chemistry $(1-6)$. For organic compounds generally a combination of derivatization, gas chromatography and selected ion monitoring mass spectrometry in the electron impact mode is employed in these reference methods.

In this study, a different approach was chosen based on the high specificity of both stable isotope dilution and field desorption mass spectrometry. The extremely soft ionization conditions in field desorption make this technique uniquely suited for qualitative and quantitative mixture analysis since a variety of low molecular biochemicals predominantly form molecular or quasimolecular ion species under the conditions of field desorption mass spectrometry (e.g. l.c. (7)) in the investigations of purified compounds as well as in the analysis of complex mixtures. In the following it is shown that the high specificity of the analytical procedure employed enables a fast and accurate quantification of total and free cholesterol in crude lipid extracts from human body fluids. 


\section{Materials and Methods}

Chemicals

Methanol, ethanol, and chloroform (zur Rückstandsanalyse) were purchased from Merck, Darmstadt, FRG. Cholesterol SRM 911a was purchased from National Bureau of Standards, Washington, USA. $3,4-\left[{ }^{13} \mathrm{C}_{2}\right.$ ] Cholesterol $\left(90\right.$ atom\% $\left.{ }^{13} \mathrm{C}\right)$ was obtained from KOR Isotopes, Cambridge, Mass., USA; its molecular ion pattern was determined to be as follows: $\left[{ }^{13} \mathrm{C}_{0}\right]: 5.8 \%$; ${ }^{13} C_{1}$ ]: $12.6 \%$; $\left[{ }^{13} C_{2}\right.$ ]: $100 \%$; $\left[{ }^{13} C_{3}\right]$ : $28.3 \%$; [ $\left.{ }^{13} C_{4}\right]: 4.1 \%$; $\left[{ }^{13} \mathrm{C}_{5}\right]: 0.4 \% .\left[{ }^{2} \mathrm{H}_{7}\right]$ Cholesterol was a generous gift of $G$. $\nu$. Unruh, Medizinische Universitätsklinik, Bonn, FRG. The label distribution of this compound was determined to be $\left[{ }^{2} \mathrm{H}_{5}\right] 0.7 \%$, $\left[{ }^{2} \mathrm{H}_{6}\right] 3.3 \%,\left[{ }^{2} \mathrm{H}_{7}\right] 95.7 \%$, corresponding to 99.7 atom\% deuterium in the isopropyl side-chain hydrogen positions.

\section{Control sera}

Control serum 1: Precilip E. L. lot 1-305/2-305/3-305/4-305 from Boehringer Mannheim GmbH, FRG. Control serum 2: product no. R-3626-S, lot no. 51F6113 from Sigma, St. Louis, USA.

\section{Extraction procedure}

Initially plasma samples were extracted according to Folch et al. (8) or using pure chloroform. For both procedures cholesterol concentrations determined by isotope dilution and mass spectrometry were identical within the precision of the method. On this basis we preferred to use an extraction with chloroform alone which was performed as follows: $50 \mu \mathrm{l}$ of plasma or $500 \mu \mathrm{l}$ of urine to which an appropriate amount of internal standard had been added were extracted two times with $1 \mathrm{ml}$ of chloroform. For each step, sample and solvent were vortexed thoroughly, centrifuged for about $3 \mathrm{~min}$ at $3000 \mathrm{~min}^{-1}$, and the chloroform phase removed. The chloroform phases were combined and dried under a stream of nitrogen. The residue was redissolved in $50 \mu \mathrm{l}$ of methylene chloride and this solution was used for mass spectrometry.

Quantitative hydrolysis of cholesterol esters was performed according to a published procedure (5): $1 \mathrm{ml}$ ethanol and $100 \mu \mathrm{l}$ aqueous $\mathrm{KOH}(6 \mathrm{~mol} / \mathrm{l})$ are added to $50 \mu \mathrm{l}$ of plasma. This mixture is kept at $+60^{\circ} \mathrm{C}$ for $1 \mathrm{~h}$ and after cooling to room temperature it is extracted as described above. Urinary cholesterol esters were hydrolysed by addition of $2.5 \mathrm{ml}$ of aqueous $\mathrm{KOH}(6 \mathrm{~mol} / \mathrm{l})$ to $500 \mu \mathrm{l}$ of sample. This mixture is incubated for $1 \mathrm{~h}$ at $60^{\circ} \mathrm{C}$, cooled to room temperature, and then extracted as the nonhydrolysed sample.

\section{Mass spectrometry}

Mass spectrometry was performed on a double focusing instrument type Vacuum Generators $\mathrm{ZAB}-1 \mathrm{~F}$ in the field desorption mode. High temperature activated carbon emitters (9) prepared on a Vacuum Generators activator by a resistance controlled activation procedure $(10)$ were used for all measurements. The average needle length of the emitter carbon micro-needles was $30 \mu \mathrm{m}$. The mass spectra were recorded electrically in the doublefocusing mode at the minimal adjustable resolution of about $500-700$. The multiplier signals were fed into a multichannel analyzer type Canberra series 80 via a digitizer model Canberra 6271 . The spectra were accumulated using repetitive magnetic scans of the mass spectrometer which triggered the multichannel analyzer sweeps. Typical data for the accumulation of selected sections of mass spectra are a dwell time of $1 \mathrm{~ms}$ per channel and the use of $2 \mathrm{~K}$ channels of the total $8 \mathrm{~K}$ memory of the multichannel analyzer. Digital read outs of peak heights were used as the basis for quantitative determinations. The mass spectra were documented using a graphic plotter (HewlettPackard 7225A). The sample solutions were applied to the field desorption emitter by a microliter syringe under stereomicroscope control at a magnification of $63 X$. For a single analysis a $2-10 \%$ aliquot of the total lipid extract from $50 \mu$ l plasma or $500 \mu 1$ of urine was used.

\section{Results and Discussion}

A crude lipid extract from human plasma contains the five main classes of plasma lipids, namely free fatty acids, free cholesterol, cholesterol esters, phospholipids, and triglycerides. In the sequence of listing, these lipids show increasing molecular weights, the single classes of compounds covering fairly well separated mass regions. Thus, in the analysis of a complex mixture containing these classes of lipids by mass spectrometry combined with a soft mode of ionization, such as field desorption, very little interference from the various molecular ion species is to be expected.

In fact, investigation of a crude chloroform extract from plasma by FD MS shows few prominent ion groups. For instance, the only strong signal occurring in the mass region between about $\mathrm{m} / \mathrm{z} 350$ to $\mathrm{m} / \mathrm{z} 600$ is found at $\mathrm{m} / \mathrm{z} 386$ representing the molecular ion of cholesterol. Except for the signals due to the natural isotopic pattern of cholesterol, the background signals on the high mass side of the molecular ion are in the order of $0.2-0.4 \%$ relative abundance, as can be derived from the mass spectrum in figure 1 . The spectrum was recorded in the range of heating currents which correspond to optimal desorption of cholesterol.

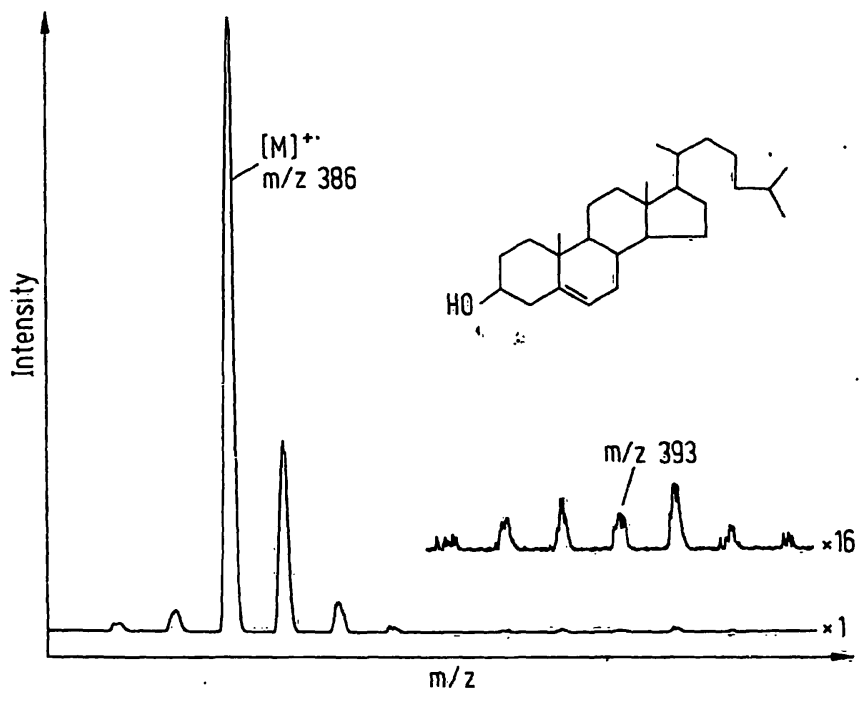

Fig. 1. Partial field desorption mass spectrum of a crude plasma lipid extract showing the molecular ion of nonesterified cholesterol. 160 Sweeps were accumulated at 14-16 mA emitter heating current.

The low level of interfering ions near the molecular ion of cholesterol allows the addition of isotopically labelled analogues as internal standards for accurate quantifica= tions (11-13). In addition, a control of the isotopic abundances of the cholesterol molecular ion pattern as shown in table 1 excludes a measurable overlapping of other compounds at the mass values 386,387 , and 388 . The minor signals at $\mathrm{m} / \mathrm{z} 385$ and 384 are due to the abstraction of one or two hydrogen atoms by surface reactions on the FD emitter.

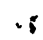


The data in table 1 also show that the precision of the isotope abundance determinations by field desorption mass spectrometry in this case is not sufficient to confirm the presence of small amounts of dihydrocholesterol, the plasma concentration of which is reported to be on average $0.7 \%$ of the cholesterol concentration (14). In the isotopic pattern of plasma cholesterol the abundance of the signal at $\mathrm{m} / \mathrm{z} 388$ appears to be slightly enhanced over the calculated value; however, a similar deviation is observed in the molecular ion pattern of authentic pure cholesterol.

Tab. 1. Comparison of calculated and experimentally observed isotopic abundances of cholesterol.

\begin{tabular}{lrrr} 
Relative intensity & Calculated & $\begin{array}{l}\text { Experimental, } \\
\text { pure } \\
\text { cholesterol }\end{array}$ & $\begin{array}{l}\text { Experimental, } \\
\text { plasma } \\
\text { cholesterol }\end{array}$ \\
\hline $\mathrm{m} / \mathrm{z} 386(\%)$ & 100 & 100 & 100 \\
$\mathrm{~m} / \mathrm{z} 387(\%)$ & 30.95 & $31.4 \pm 0.5$ & $31.5 \pm 0.6$ \\
$\mathrm{~m} / \mathrm{z} \mathrm{388}(\%)$ & 4.82 & $5.6 \pm 0.6$ & $5.4 \pm 0.4$ \\
\hline
\end{tabular}

Both deuterated and ${ }^{13} \mathrm{C}$-labelled cholesterol were available as internal standards. With respect to similarity in physico-chemical properties, the ${ }^{13} \mathrm{C}$-labelled compound is to be preferred, as it is characterized by even smaller differences from the naturally occurring cholesterol than is the deuterated compound. On the other hand, the molecular ion group of $\left[{ }^{2} \mathrm{H}_{7}\right]$ cholesterol is completely separated from the group of endogenous cholesterol, whereas the pattern of $\left[{ }^{13} \mathrm{C}_{2}\right]$ cholesterol shows a significant amount of overlap with the ion signals of the nonlabelled compound. Thus, the use of the heptadeuterated analogue allows a more simple quantitative evaluation of the mass spectra.

To verify the suitability of these standards for quantitative measurements, calibration curves covering the concentration ratios of interest were established. Reference cholesterol with a specified purity of $99.8 \pm 0.1 \%$ was used for preparation of standard solutions of nonlabelled material. For each quantitative determination the complete desorption of the sample was accumulated to compensate possible isotope effects during desorption especially for the mixtures containing the heptadeuterated compound (15). Figure 2 shows the calibration curve obtained for the use of $\left[{ }^{2} \mathrm{H}_{7}\right]$ cholesterol as internal standard.

As expected; the calibration curve in figure 2 shows a linear relation between peak heights and molar concentrations with a correlation coefficient very close to unity and a zero intercept, because the ion groups are completely separated from each other.

In the investigations of calibration mixtures containing the $\left[{ }^{13} \mathrm{C}_{2}\right]$ labelled analogue an excellent agreement between calculated and experimentally observed isotopic patterns was also obtained. In this case, quantitative evaluation of the mixture patterns was performed by solving a system of linear equations taking into account the experimental

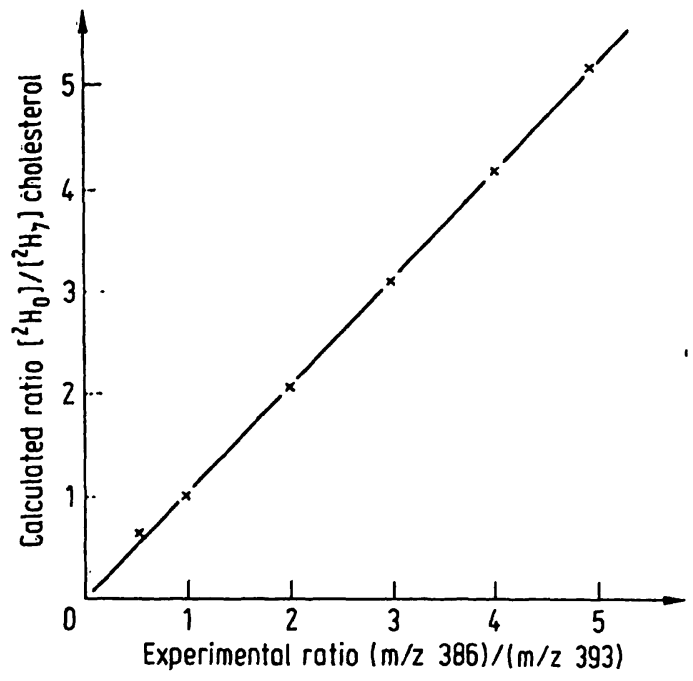

Fig. 2: Calibration curve for cholesterol quantification using $\left[{ }^{2} \mathrm{H}_{7}\right]$ cholesterol as internal standard. For each quantification 300 sweeps were accumulated at $12-18 \mathrm{~mA}$.

patterns of both sample and standard plus the small and slightly variable amount of $[\mathrm{M}-\mathrm{H}]^{+}$and $[\mathrm{M}-2 \mathrm{H}]^{+}$formation. With respect to these calibration mixtures, deuterated and ${ }^{13} \mathrm{C}$-labelled cholesterol were found to be i equally well suited as internal standards for cholesterol quantifications by FD MS. Arbitrarily, we used the $\left[{ }^{2} \mathrm{H}_{7}\right]$ standard for plasma cholesterol determinations and the $\left[{ }^{13} \mathrm{C}_{2}\right]$ standard for measurements of urinary cholesterol.

In the investigations of plasma samples for free and total cholesterol, a significant difference was observed between hydrolysed and nonhydrolysed samples. This difference was found in the mass region where the loss of water from the protonated cholesterol occurred. Figure 3 illustrates this effect.

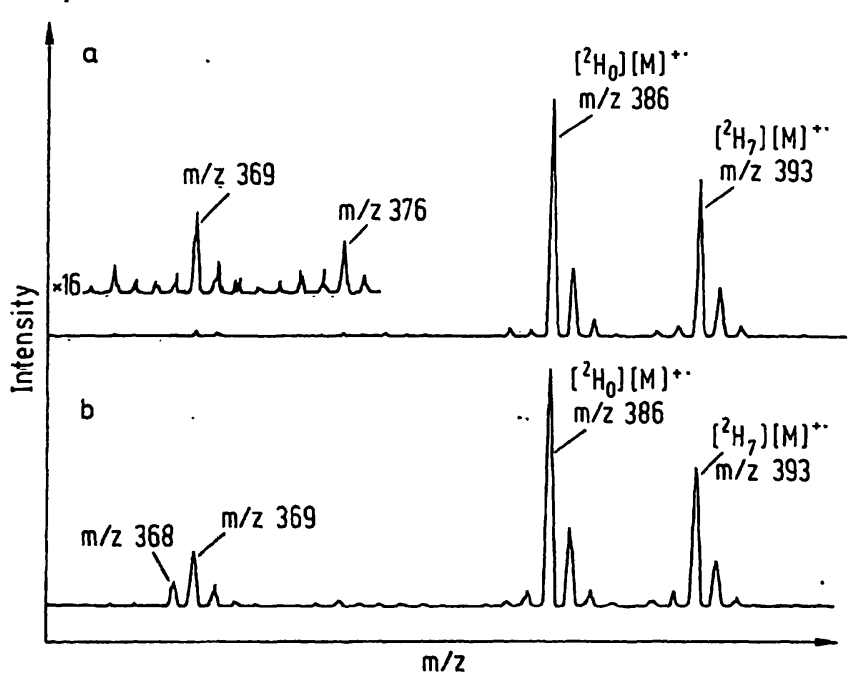

Fig. 3. Molecular ion region of cholesterol produced by field desorption mass spectrometry of a crude chloroform extract from control serum $1 ; 200$ siveeps were accumulated at 16-18 $\mathrm{mA}$ emitter heating current:

a) after hydrolysis, $40 \mu \mathrm{l}$ standard solution added to $20 \mu \mathrm{l}$ of serum;

b) without hydrolysis, $20 \mu$ of standard solution added to $50 \mu$ of serum. 
Tho ion signals at $\mathrm{m} / \mathrm{z} 386$ and $\mathrm{m} / \mathrm{z} 393$ correspond to the molecular ions of endogenous cholesterol and of the heptadeuterated internal standard, respectively. The loss of water from the protonated molecules of cholesterol is observed with relative abundance of about $2 \%$ at $\mathrm{m} / \mathrm{z} 369$ and $\mathrm{m} / \mathrm{z} 376$ and the relative intensitics of these fragment ions show the same intensity ratio as the corresponding molecular species, as can be seen in figure 3a. However, in figure $3 \mathrm{~b}$ the group of fragment ions additionally shows the presence of two signals of roughly equal relative intensity of ca. $5 \%$ at $\mathrm{m} / \mathrm{z} 368$ and $\mathrm{m} / \mathrm{z} 369$, which do not originate from cholesterol. We found these ions to be due to the fragmentation of cholesterol esters, which are an important constituent of the lipid extract from nonhydrolysed samples. The quantitatively most important cholesterol ester in human plasma is cholesteryl linoleate (16) with an abundance of ca. $50 \%$ among the cholesterol fatty acid esters.

Inspection of the FD mass spectrum of authentic cholesteryl linoleate at heating currents between 14 and $18 \mathrm{~mA}$ corresponding to optimal desorption of cholesterol, revealed the formation of two fragment ions of about equal intensity at $\mathrm{m} / \mathrm{z} 368$ and $\mathrm{m} / \mathrm{z} 369$ with ca. $5 \%$ relative abundance; in addition, a fragment at $\mathrm{m} / \mathrm{z}$ 386 is observed with about $2.5 \%$ relative intensity. Consequently, in quantifications of nonesterified cholesterol the ions in the mass region between $\mathrm{m} / \mathrm{z} 360$ and $\mathrm{m} / \mathrm{z}$ 400 were accumulated and from the peak height at $\mathrm{m} / \mathrm{z}$ 386 fifty percent of the peak height at $\mathrm{m} / \mathrm{z} 368$ was subtracted to compensate for the small amount of superposition from the cholesterol ester fragment ion. In the investigation of hydrolysed plasma samples the peak heights at $\mathrm{m} / \mathrm{z} 386$ and $\mathrm{m} / \mathrm{z} 393$ were used directly for the calculation of total cholesterol levels.

Table 2 summarizes the quantitative data obtained in the investigation of two control sera and gives a comparison with the assigned concentration data.

Tab. 2. Cholesterol levels in two control sera determined by field desorption mass spectrometry and comparison with assigned values.

Nonesterified cholesterol

$$
\begin{aligned}
& \text { Field desorption } \\
& \text { mass spectrometry }{ }^{1} \text { ) }
\end{aligned}
$$

Control serum $\left.1 \quad 1.39 \pm 0.03 \mathrm{mmol} / \mathrm{l}^{3}\right) \quad 1.47 \pm 0.20 \mathrm{mmol} / 1$

Total cholesterol

$$
\text { Field desorption Enzymatic }{ }^{4} \text { ) }
$$

Control serum 1 mass spectrometry

\section{$6.32 \pm 0.62 \mathrm{mmol} / \mathrm{l}$} $\begin{array}{lll}3.55 \pm 0.08 \mathrm{mmol} / 1 & \left.3.57^{5}\right) \quad \mathrm{mmol} / \mathrm{l}\end{array}$

1) average of 4 determinations

$\left.{ }^{2}\right)$ cholesterol oxidase/catalase without hydrolysis

3) error limits correspond to \pm 2 sigma

${ }^{4}$ ) cholesterol oxidase/catalase with enzymatic hydrolysis

5) no error limits specified
All data produced by mass spectrometric quantification are within the error limits of the assigned values of the control sera. The mass spectrometric data are characterized by standard deviations of around $\pm 2 \%$ for a single determination. This is a common value for the employed isotope dilution methodology and a significantly higher precision than that observed in the enzymatic routine test. Moreover, due to the high specificity of the mass spectrometric detection and due to the principle of internal standardization using a stable isotope labelled analogue, the quantitative data produced by this methodology are also characterized by a high accuracy.

\section{Plasma cholesterol esters}

Besides nonesterified cholesterol, a crude chloroform extract of nonhydrolysed human plasma also contains the variety of intact cholesterol fatty acid esters. Therefore, the FD mass spectrum of this extract shows a characteristic pattern of the molecular ions of these esters which is displayed in figure 4.

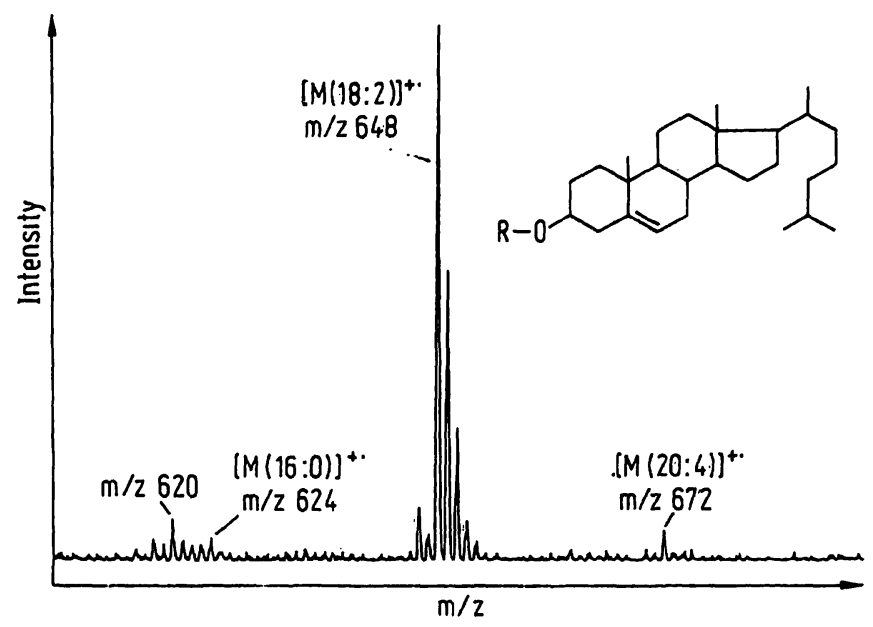

Fig. 4. Field desorption mass spectrum of plasma cholesteryl esters containing long chain fatty acids; 100 sweeps were accumulated at 16-20 mA emitter heating current.

Except for the small group of ions around $\mathrm{m} / \mathrm{z} 620$ which are tentatively assigned as molecular ions of diglycerides or as fragment ions of triglycerides, the spectrum in figure 4 shows the molecular ions of cholesterol esters. The most prominent signal is found at $\mathrm{m} / \mathrm{z} 648$ corresponding to the molecular ion of cholesteryl linoleate, which is the most abundant plasma cholesterol ester. In the pattern around this ion the presence of minor amounts of the linolenate and oleate esters is further indicated by the signal at $\mathrm{m} / \mathrm{z}$ 646 and by the intensity of the ion at $\mathrm{m} / \mathrm{z} 650$ which is enhanced over the natural isotopic abundan'e in the cholesteryl linoleate pattern.

In addition to this group of cholesterol $C_{18}$-esters small amounts of cholesteryl palmitate at $\mathrm{m} / \mathrm{z} 624$ and of cholesteryl arachidonate at $\mathrm{m} / \mathrm{z} 672$ aje found. The in- 
tensities of the molecular ion signals of the cholesterol esters in figure 4 are in rough quantitative agreement with the average data of the fatty acid distribution of human plasma cholesterol esters $(16,17)$. The FD molecular ion pattern in figure 4 shows a good reproducibility, but it does not directly provide quantitative information because FD sensitivity differs significantly for the various types of cholesterol esters. For instance, FD sensitivity increases with increasing number of double bonds in cholesterol esters. Another fact hampering a straightforward quantification of cholesterol long chain fatty acid esters is the lack of a commercial source of appropriately labelled cholesterol esters, such as cholesteryl linoleate.

\section{Urinary free and total cholesterol}

Small amounts of cholesterol are also found in urine and they mainly originate from traces of mucous secretions. Daily urinary cholesterol excretion is in the order of $1 \mathrm{mg} / 24 \mathrm{~h}$, and the correlation of enhanced values with a variety of diseased states has been attempted (e.g. 1.c. (18)). Whèreas plasma levels of nonesterified and total cholesterol are characterized by a ratio of about $1: 3$, the corresponding ratio in urine is about 1:1.2 (19).

We observed that urine levels of cholesterol, which normally are about three orders of magnitude lower than plasma levels, can also be quantified by field desorption mass spectrometry using the same simple extraction procedure as for plasma samples. The molecular ion pattern of cholesterol generated from these urinary extracts does not show a measurable superposition of interfering ions and therefore is identical to that given in figure 1 and to the data in table 1 , respectively. In this case we used $\left[{ }^{13} \mathrm{C}_{2}\right]$ cholesterol as internal standard for the quantifications. Figure 5 shows the isotopic patterns obtained from two aliquots of a 24 h urine sample of an apparently healthy volunteer.

Comparison of the molecular ion groups in figures $5 \mathrm{a}$ and $5 \mathrm{~b}$ clearly shows a slightly enhanced level of cholesterol in the hydrolysed sample compared to the unprocessed sample. Evaluation of the cholesterol levels in these samples gave an excretion of $0.32 \mathrm{mg} / 24 \mathrm{~h}$ for free and of $0.46 \mathrm{mg} / 24 \mathrm{~h}$ for total cholesterol. These values are within the range of normal values for cholesterol excretion determined for healthy controls by a gas chromatographic method (19).

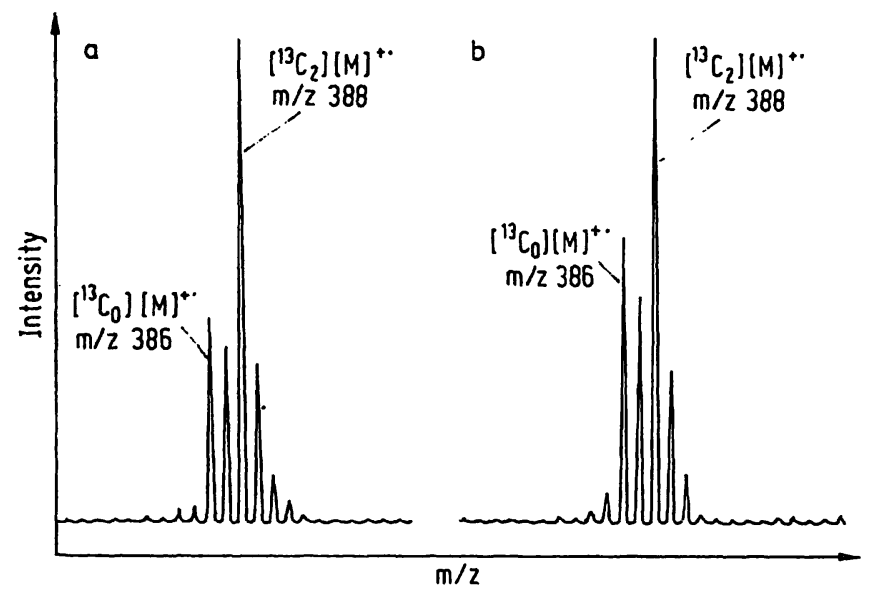

Fig. 5. Quantification of urinary cholesterol using $\left[{ }^{13} \mathrm{C}_{2}\right]$ cholesterol as internal standard; 250 sweeps were accumulated at 14-16 mA emitter heating current. a) without hydrolysis; b) after hydrolysis.

\section{Conclusion}

The results show that field desorption mass spectrometry can be used for a fast and highly accurate quantification of free and total cholesterol in small samples of plasma and urine. Due to the outstanding specificity of the mass spectrometric ionization procedure employed, only a simple extraction step and no chromatographic purification of the extract is necessary. Being more expensive and more sophisticated than routine clinical chemical assays for cholesterol quantification, this method should preferentially be used in studies essentially requiring highly precise and accurate quantitative data or in investigations where only extremely small amounts of sample are available.

\section{References}

1. Moore, L. J. \& Machlan, L. A. (1972) Anal. Chem. 44, 2291-2296.

2. Björkhem, I., Blomstrand, R. \& Svensson, L. (1974) Clin. Chim. Acta 54, 185-193.

3. Siekmann, L., Hüskes, K. P. \& Breuer, H. (1976) Fresenius Z. Anal. Chem. 279, 145-146.

4. Gambert, P., Lallemant, C., Archambault, A., Maume, B. F. \& Padieu, P. (1979) J. Chromatogr. 162, 1-6.

5. Cohen, A., Hertz, H. S., Mandel, J., Paule, R. C., Schaffer, R., Sniegoski, L. T., Sin, T., Welch, M. J. \& White V, E. (1980) Clin. Chem. 26, 854-860.

6. Schaffer, R., Sniegoski, L. T., Welch, M. J., White V, E., Cohen, A., Hertz, H. S., Mandel, J., Paule, R. C., Svensson, L., Björkhem, I. \& Blomstrand, R. (1982).Clin. Chem. 28, 5-8.

7. Schulten, H.-R. (1979) Int. J. Mass Spectrom. Ion Phys. 32, 97-283.

8. Folch, J., Lees, M. \& Sloane Stanley, G. H. (1957) J. Biol. Chem. 226, 497-509.

9. Schulten, H.-R. \& Beckey, H. D. (1972) Org. Mass Spectrom. $6,885-895$.

10. Lehmann, W. D. \& Fischer, R. (1981) Anal. Chem. 53, 743-747.

11. Millard, B. J., Quantitative Mass Spectrometry, Heyden, London, 1978.

12. Lehmann, W. D. \& Schulten, H.-R. (1978) Angew. Chem. 90, 233-250; Angew. Chem. Int. Ed. Engl. 17, 221-238.

13. DeLeenheer, A. P., Cruyl, A. A. (1980) in: Biochemical Applications of Mass Spectrometry (Waller, G. R. \& Dermer, O. C., eds.) First Supplementary Volume, Wiley, New York, pp. 1169-1207. 
14. Chattopadhyay, D. P. \& Mosbach, E. H. (1965) Anal. Biochem. 10, 435-443.

15. Lehmann, W. D. \& Schulten, H.-R. (1978) Biomed. Mass Spectrom. 5, 208-214.

16. Schrade, W., Böhle, E., Biegler, R., Teicke, R. \& Ullrich, B. (1960) Klin. Wochenschr. 38, 739-753.

17. Perkins, E. G., Hendren, D. J., Bauer, J. E. \& El-Hamdy, A. H. (1981) Lipids 16, 609-613.
18. Acevedo, H. F., Campbell, E. A., Frich, J. C. Jr., Merkow, L. P., Hayeslip; D. \& Gilmore, J. (1975) Cancer 36, 1459-1469.

19. Jüngst, D., Wallner, J., Pickel, A., Stadtler, A., Eiermann, W., Marx, F. J. \& Karl, H. J. (1981) Klin. Wochenschr. 59, $545-552$.

D̈r. W. D. Lehmann

Abteilung Medizinísche Biochemie Institut für Physiologische Chemie

Universitäts-Krankenhaus-Eppeñndorf̣ Martiniștr. 52

D-2000 Hamburg 20 